\title{
Physical activity as a protective factor for development of non-alcoholic fatty liver in men
}

\author{
Atividade física como fator de proteção para o desenvolvimento de esteatose hepática \\ não alcoólica em homens
}

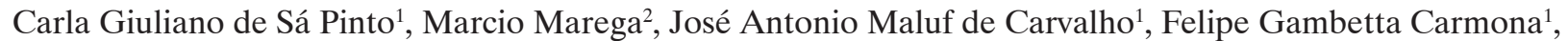
Carlos Eduardo Felix Lopes ${ }^{1}$, Fabio Luis Ceschini², Danilo Sales Bocalini², Aylton José Figueira Junior ${ }^{2}$
\end{abstract}

\begin{abstract}
Objective: To determine the impact of physical activity on the prevalence of fatty liver, metabolic and cardiovascular disease in adult men. Methods: This study evaluated 1,399 men $(40.7 \pm 8.18$ years) with body mass index of $26.7 \mathrm{~kg} / \mathrm{m}^{2}( \pm 3.4)$ who participated in the Protocol of Preventive Health Check-up at Hospital Israelita Albert Einstein from January to October 2011. We conducted tests of serum blood glucose, total cholesterol, LDL, HDL, triglycerides, reactive c-protein, aspartate transaminase, alanine transaminase and gamma-glutamyl transpeptidase. The statistical analysis comprised in the comparison of mean and standard deviation. The analysis of variance was based in two paths of two way ANOVA, Student's $t$-test, Mann Whitney U test, Wald test and $\chi^{2}$. We considered a significance level at $p<0.05$ and correlation of univariate Poison with $95 \%$ confidence interval. Results: Fatty liver was diagnosed in $37.0 \%$ of the sample. Triglyceride levels of active men with fatty liver were $148.2 \pm 77.6 \mathrm{mg} / \mathrm{dL}$ while inactive men with fatty liver had $173.4 \pm 15.6 \mathrm{mg} / \mathrm{dL}$. The remaining serum levels were normal. Inactive individuals showed higher values than active. In addition, inactive individuals have 10.68 times higher risk of developing fatty liver compared with active. Conclusion: Physical activity improves metabolic parameters such as triglycerides, weight control, HDL, which interfere in the development of fatty liver. Physically active individuals had lower fatty liver prevalence regardless of values of body composition and lipid profile, leading the conclusion that
\end{abstract}

physical activity has a protective role against development of fatty liver.

Keywords: Fatty liver; Motor activity; Exercise; Metabolic diseases

\section{RESUMO}

Objetivo: Determinar o impacto do nível de atividade física na prevalência de esteatose hepática, perfil metabólico e comportamento cardiovascular em homens adultos. Métodos: Foram avaliados 1.399 homens $\left(40,7 \pm 8,18\right.$ anos) com índice massa corporal de $26,7 \mathrm{~kg} / \mathrm{m}^{2}$ $( \pm 3,4)$ pelo protocolo da Revisão Continuada de Saúde do Hospital Israelita Albert Einstein entre janeiro a outubro de 2011. Foram realizadas análise séricas de glicose sanguínea, colesterol total e séries, triglicerídeos, RCP, ALT, AST e Gama-GT. A análise estatística utilizada consistiu na comparação de média e desvio padrão. A análise de variância de dois caminhos ANOVA two way, teste $t$ de Student, teste U Mann Whitney, teste de Wald e teste $\chi^{2}$, sendo 0 nível de significância $p<0,05$ e correlação univariada de Poison, com intervalo de confiança de $95 \%$. Resultados: Os resultados demonstraram que $37,0 \%$ da amostra apresentou diagnóstico de esteatose hepática. Homens ativos com esteatose hepática apresentaram níveis de triglicerídeos de $148,2 \pm 77,6 \mathrm{mg} / \mathrm{dL}$ enquanto os inativos com esteatose hepática apresentaram $173,4 \pm 15,6 \mathrm{mg} / \mathrm{dL}$. 0s demais níveis séricos apresentaram-se dentro dos padrões

\footnotetext{
${ }^{1}$ Hospital Israelita Albert Einstein, São Paulo, SP, Brazil.

2 Universidade São Judas Tadeu, São Paulo, SP, Brazil.

Corresponding author: Carla Giuliano de Sá Pinto - Rua Madre Cabrini, 462, Vila Mariana - Zip code: 04020-001 - São Paulo, SP, Brazil - Phone: (55 11) 2151-7200 - E-mail: carla.giuliano@einstein.br Received on: June 24, 2013 - Accepted on: Jan 7, 2014
} 
considerados saudáveis, porém os inativos apresentaram todos os valores superiores, em relação aos ativos. Apontou-se que indivíduos inativos apresentam 10,68 vezes maior risco em desenvolver esteatose hepática em relação aos ativos. Conclusão: $A$ atividade física melhora os indicadores metabólicos, como triglicérides, controle de peso, HDL, que interferem no desenvolvimento de esteatose hepática, mostrando que indivíduos fisicamente ativos apresentaram menor prevalência de esteatose hepática independentemente dos valores de composição corporal e perfil lipídico, concluindo que a atividade física apresenta papel protetor no desenvolvimento de esteatose hepática.

Descritores: Fígado gorduroso; Atividade motora; Exercício; Doenças metabólicas

\section{INTRODUCTION}

Chronic non-communicable diseases are characterized as sings of worsening in individuals' health conditions. Currently, fatty liver is considered one of them. Fatty liver is defined as an accumulation of lipids within hepatocytes when, by histopathological analysis, exceeds $5 \%$ of liver weight. Because fatty liver promotes the development of hepatic lesions it is considered one of the major causes of chronic liver diseases in adults. In the United States fatty liver has an prevalence of $31 \%$ among adults, and of these $50 \%$ have diabetics and $76 \%$ are obese. ${ }^{(1)}$ In the world, $10 \%$ to $24 \%$ of adults of both sexes have positive diagnosis to fatty liver, ${ }^{(2)}$ which can be related with unhealthy life habits, such as poor diet and low level of physical activity.

Physical inactivity is prevalent in $70 \%$ of adult population living at large urban areas both at developed and under development countries. For this reason, it constitutes the main risk factor for the development of chronic non-communicable diseases. ${ }^{(3)}$ Individuals with fatty liver have abnormalities in triglycerides serum levels, high-density lipoprotein cholesterol (HDL-c) and waist circumference, in addition to be physical inactive, which strengthen even more the fatty liver occurrence. Regular exercise shows positive effects to improve lipid profile, ${ }^{(4,5)}$ although positive results to control fatty liver still inconclusive.

No consensus exists concerning specific drug treatment for fatty liver, however, as non-drug treatment, patients are advised to reduce intake of fat and to exercise regularly to reduce body weight and improve lipid profile, ${ }^{(6)}$ in order to promote reduction of insulin resistance. $^{(1)}$

Hence, physical activity in individuals with fatty liver aim to reduce body weight and improve muscular strength to increase insulin sensitivity, as observed in individuals with metabolic syndrome. ${ }^{(7)}$
Evidences presented by Belmonte et al. ${ }^{(4)}$ and Lira ${ }^{(5)}$ suggest the importance of moderate aerobic activity as a preventive agent in installation of fatty liver because of the reestablishment of metabolism of lipoprotein and increase in the mitochondrial ability to transport fatty acids in hepatocytes, however there is a lack of enough studies showing the relationship between level of exercise and prevalence of fatty liver in adults. Such thing occurs because according to Colberg et al., ${ }^{(8)}$ the increase of physical activity level improves the control of glycemic levels due to use of glucose in muscle tissue, liver gluconeogenesis, insulin independent uptake, weight control, stimulus of GLUT proteins and active kinase protein. For this reason, the practice of mild to moderate aerobic exercise is recommended for at least 150 minutes weekly, including home activities, movements and structured activities. Exercises of resistance with moderate intensity must be done twice a week in alternated days ${ }^{(8)}$ but each individual clinical characteristic should be considered.

\section{OBJECTIVE}

To determine the impact of physical activity on the prevalence of fatty liver, metabolic and cardiovascular disease in adult men.

\section{METHODS}

We evaluated retrospectively medical records of 1,399 men $(40.7 \pm 8.18$ years old) who were not diabetics and had alcohol consumption classified as no higher than intermediate. These individuals participated in the protocol of Preventive Health Check-up at Hospital Israelita Albert Einstein from January to October 2011.

Participants underwent several exams and evaluations including anthropometric, metabolic and serial measures.

Anthropometric evaluation determined body mass $(\mathrm{kg})$, height $(\mathrm{cm})$, waist circumference $(\mathrm{cm})$ and body mass index $\left(\mathrm{kg} / \mathrm{m}^{2}\right)$. Weight was determined using the Ottoboni Inbody 230 Body Composition Scale. In the weight evaluation, the individual was wearing light clothing and no shoes. Height was determined using a stadiometer with a precision of $0.1 \mathrm{~mm}$. Individuals were measured with heels, buttocks, scapula and occipital surface touching the wall. In addition, participant was making inspiratory apnea, looking ahead and, at this moment, the evaluator did the measurement placing the stadiometer on top of individual's head.

Measure was done three times, and the final result was a mean of three measures. To conduct measurement of waist circumference, the individual was kept in ostotastic position with relaxed abdomen. The tape 
measure was placed in horizontal plan in medium point between last costal arch and iliac crest. The final result was calculated based on the mean of three measurements previously conducted. Anthropometric values of body weight and height were used to calculate the body mass index $\left(\mathrm{BMI}=\mathrm{kg} / \mathrm{m}^{2}\right)$ that classified obesity according to 2004 guidelines stated by the World Health Organization (WHO) for adults, being: eutrophic if 18.5 to $24.9 \mathrm{~kg} / \mathrm{m}^{2}$, overweight if 25.0 to $29.9 \mathrm{~kg} / \mathrm{m}^{2}$, and obese if over $30.0 \mathrm{~kg} / \mathrm{m}^{2}$.

Metabolic assessment diagnosed the maximal aerobic power (in METS), by maximal ergometric test according to the Ellestad/Memorial protocol. ${ }^{(9)}$

Systolic and diastolic blood pressure $(\mathrm{mmHg})$ were measured with patients' seated after resting for 5 minutes, appropriate cuff width in relation to arm circumference and previously calibrated aneroid sphygmomanometer, as stated by the guidelines of Brazilian Society of Hypertension. ${ }^{(10,11)}$ Other two measures were done in different moments, and mean value obtained was considered as the final value. In case of discrepant measures (different greater than $5 \mathrm{mmmHg}$ ) the most close values were used to calculate the mean.

Serum assessment included in blood samples collected after a 12-hour fast. We obtained, using the methods listed below, dosages of total cholesterol, highdensity lipoprotein, triglycerides: enzymatic - dried chemical; uric acid: colorimetric (Uricase) - Fusion Dried chemical; Glycemia: Enzimatic (GOD-POD) Fusion - Dried Chemical; high-density lipoprotein: measured by Friedewald formula; liver enzyme: Aspartate transaminase, Alanine transaminase, gammaglutamyl transpeptidase (AST, ALT, Gamma GT): Enzimatic - Fusion - Dried chemical, Reactive C-protein (RCP): Turbidimetry (Vitros Fusion 5.1 FS).

Fatty liver was considered present when it was detected by the abdominal ultrasonography, which evaluated the form and conservation of the liver. Individuals were classified as those who had fatty liver and those who had not fatty liver.

We classified as metabolic syndrome those individuals with three or more criteria based on Third Report of the Expert Panel on Detection, Evaluation, and Treatment of High Blood Cholesterol in Adults (Adult Treatment Panel III). ${ }^{(12)}$

The consume of alcohol was evaluated using the questionnaire of Alcohol Use Disorder Identification Test, ${ }^{(13)}$ that classifies in low, intermediate and high the daily alcohol consumption of these individuals, followed by WHO recommendations on non-harmful consumption. The level of physical activity was determined by the short version of the International Physical
Activity Questionnaire, ${ }^{(14)}$ fulfilled by physical educator during the Preventive Health Check-up consultation, being classified as active those individuals who had 150 minutes of physical activity weekly, and inactive those who did not reach the recommendation.

All participants signed the consent term respecting ethical and legal aspects of research on human subjects, according to the Declaration of Helsinki. This study was approved by the Ethical Committee, number CAAE: 28948314.1.0000.0071 and legal advice number 633.479.

Data were analyzed using the Statistical Package for the Social Sciences (SPSS) version 17.0. Categorical variables were expressed in absolute variables and percentages. Continual variables were presented in means and standard deviations if parametrical or medium, if non-parametrical they were presented in minimal and maximal values.

The comparison of continuing variables between two groups were done using the $t$ test or Mann-Whitney test, based on the nature of distribution.

Wald test was used to assess heterogeneity of odds ratio for the development of fatty liver. Statistical significance level was defined as $5 \%$ for all tests $(\mathrm{p}<0.05)$.

\section{RESULTS}

Assessments were done considering that physical inactivity, serum, metabolic and anthropometric changes can contribute with fatty liver prevalence. Individuals' demographic characteristics in table 1 showed normality in most of serum, metabolic and anthropometrical data that suggested low functional compromising of the sample.

However, the analysis of anthropometrical and biochemical variables showed that value of BMI represented weight excess over of what is healthy. Total cholesterol, triglycerides, low density lipoprotein and high-density lipoprotein were closed to values considered healthy. Results of hepatic enzyme and RCP were normal.

In our sample, $46 \%$ of individuals were aged 30 to 39 years; $52.2 \%$ had excess weight and $15.1 \%$, some degree of obesity; $37 \%$ of adults were diagnosed with fatty liver; $15.6 \%$ with present metabolic syndrome and $69.4 \%$ were physically inactive.

In table 2, we had anthropometrical characteristics of men physically active and inactive with and without diagnosed fatty liver.

Results showed significant difference between active patients with fatty liver and those who had no fatty liver. In addition, differences were seen in values of body 
weight (79.8 and $88.3 \mathrm{~kg})$ and BMI (25.5 and $\left.28.4 \mathrm{~kg} / \mathrm{m}^{2}\right)$, respectively, being the two groups classified in excess

Table 1. Serum, metabolic and anthropometrical profile in adult men

\begin{tabular}{lcc}
\hline \multirow{2}{*}{ Variables } & \multicolumn{2}{c}{ Male } \\
\cline { 2 - 3 } & $\mathbf{X}$ & SD \\
\hline Age (years) & 40.7 & 8.0 \\
Body weight $(\mathrm{kg})$ & 83.9 & 12.4 \\
Height (cm) & 177.4 & 6.4 \\
Body mass index (kg/m²) & 26.7 & 3.4 \\
Waist circumference $(\mathrm{cm})$ & 94.9 & 9.6 \\
Systolic blood pressure $(\mathrm{mmHg})$ & 117.4 & 10.7 \\
Diastolic blood pressure $(\mathrm{mmHg})$ & 76.7 & 7.1 \\
Aerobic power (MET) & 14.6 & 4.1 \\
Glucose & 88.0 & 9.2 \\
Total cholesterol & 202.8 & 38.2 \\
High-density lipoprotein & 46.0 & 10.3 \\
Low density lipoprotein & 129.5 & 34.3 \\
Triglycerides & 137.4 & 88.4 \\
Aspartate transaminase & 30.9 & 19.2 \\
Alanine transaminase & 44.4 & 25.3 \\
Gamma-glutamyl transpeptidase & 36.9 & 25.9 \\
Reactive C-protein & 1.9 & 3.1 \\
\hline X: & &
\end{tabular}

$\mathrm{X}$ : mean; SD: standard deviation. weight. However, values found in individuals with fatty liver were closer to borderline criteria in obese classification.

Considering that serum indicators important as reference in the diagnosis and treatment of metabolic disease, table 3 shows values of serum profile between active and inactive individuals with or without fatty liver.

Data showed that, because of the level of physical activity and fatty liver, cardiologic variable had significant differences in systolic blood pressure and diastolic blood pressure between active individuals with fatty liver and active individuals without fatty liver, although in both groups classification was normal. Aerobic power evaluated in metabolic units indicated significant difference, being that adults with fatty liver had maximal value of 17.0METs, whereas in fatty liver the value found was 14.8METs. This value is higher in inactive men without fatty liver (14.2METs). Comparing inactive men with fatty liver and inactive men without fatty liver, we found that the first group had low value of METs compared with the second group. RCP levels did not present significant different between active and inactive individuals. Men with fatty liver, even with values considered healthy, had higher means than men without fatty liver.

Table 2. Anthropometry, level of physical activity and fatty liver

\begin{tabular}{|c|c|c|c|c|}
\hline \multirow[b]{2}{*}{ Variables } & \multicolumn{2}{|c|}{ Active $(n=428)$} & \multicolumn{2}{|c|}{ Inactive $(n=971)$} \\
\hline & $\begin{array}{l}\text { Lack of fatty liver } \\
\qquad \mathrm{X} \pm \mathrm{SD}\end{array}$ & $\begin{array}{c}\text { Presence of fatty liver } \\
\qquad \mathrm{X} \pm \text { SD } \\
\end{array}$ & $\begin{array}{l}\text { Lack of fatty liver } \\
\qquad X \pm S D\end{array}$ & $\begin{array}{l}\text { Presence of fatty live } \\
\qquad X \pm S D \\
\end{array}$ \\
\hline Age (years) & $40.4 \pm 8.5$ & $42.7 \pm 9.3$ & $39.3 \pm 7.4$ & $42.2 \pm 7.8^{*}$ \\
\hline Body weight $(\mathrm{kg})$ & $79.8 \pm 10.0$ & $88.3 \pm 11.6^{*}$ & $80.5 \pm 11.2$ & $90.4 \pm 12.6^{*}$ \\
\hline Height (cm) & $177.3 \pm 6.1$ & $176.6 \pm 6.5$ & $177.4 \pm 6.8$ & $177.5 \pm 6.3$ \\
\hline $\mathrm{BMI}\left(\mathrm{kg} / \mathrm{m}^{2}\right)$ & $25.5 \pm 2.7$ & $28.4 \pm 3.3^{*}$ & $25.7 \pm 3.0$ & $28.7 \pm 3.4^{*}$ \\
\hline Waist circumference $(\mathrm{cm})$ & $90.5 \pm 7.5$ & $93.3 \pm 8.1$ & $95.4 \pm 8.6$ & $103.2 \pm 10.2^{*}$ \\
\hline
\end{tabular}

${ }^{*} p<0.05$ intergroup independent $t$ test. X: mean; SD: standard deviation.

Table 3. Serum profile and enzimatic active and sedentary men, presence of fatty liver

\begin{tabular}{|c|c|c|c|c|}
\hline \multirow{3}{*}{ Variables } & \multicolumn{2}{|c|}{ Active } & \multicolumn{2}{|c|}{ Inactive } \\
\hline & Lack of fatty liver & Presence of fatty liver & Lack of fatty liver & Presence of fatty liver \\
\hline & $X \pm S D$ & $X \pm S D$ & $X \pm S D$ & $X \pm S D$ \\
\hline Low density lipoprotein & $124.2 \pm 33.3$ & $134.1 \pm 36.5$ & $133.0 \pm 36.1$ & $129.7 \pm 32.7^{*}$ \\
\hline High-density lipoprotein & $49.3 \pm 11.5$ & $42.7 \pm 7.3^{*}$ & $47.0 \pm 9.8$ & $42.5 \pm 38.1^{*}$ \\
\hline Total cholesterol & $195.5 \pm 36.5$ & $205.6 \pm 40.1$ & $204.7 \pm 38.8$ & $206.6 \pm 38.1$ \\
\hline Triglycerides & $109.5 \pm 57.5$ & $148.2 \pm 77.6^{*}$ & $123.7 \pm 63.4$ & $173.4 \pm 15.6^{*}$ \\
\hline Glycemia & $86.3 \pm 7.0$ & $88.8 \pm 8.3^{*}$ & $86.4 \pm 7.5$ & $90.8 \pm 11.5^{*}$ \\
\hline Gamma-glutamyl transpeptidase & $31.3 \pm 19.6$ & $40.3 \pm 22.1^{*}$ & $34.9 \pm 25.1$ & $43.2 \pm 30.1^{*}$ \\
\hline Aspartate transaminase & $31.5 \pm 26.1$ & $30.5 \pm 6.4$ & $28.7 \pm 15.1$ & $32.8 \pm 16.6^{*}$ \\
\hline Alanine transaminase & $39.4 \pm 16.0$ & $46.1 \pm 15.5^{*}$ & $40.7 \pm 28.6$ & $51.9 \pm 26.5^{*}$ \\
\hline Systolic blood pressure (mmHg) & $115.3 \pm 9.7$ & $120.9 \pm 8.9 *$ & $115.6 \pm 10.6$ & $120.7 \pm 10.9^{*}$ \\
\hline Diastolic blood pressure $(\mathrm{mmHg})$ & $75.2 \pm 6.1$ & $79.2 \pm 6.6^{*}$ & $75.7 \pm 7.1$ & $78.7 \pm 7.3^{*}$ \\
\hline METs (Aerobic power) & $17.0 \pm 4.9$ & $14.8 \pm 3.9^{*}$ & $14.2 \pm 3.5$ & $13.1 \pm 2.9^{*}$ \\
\hline $\mathrm{RCP}(0-3,0 \mathrm{mg} / \mathrm{dL})$ & $1.3 \pm 2.1$ & $1.9 \pm 1.8$ & $1.8 \pm 2.7$ & $2.4 \pm 4.0^{*}$ \\
\hline
\end{tabular}

\footnotetext{
${ }^{*} p<0.05$ intergroup independent $t$ test. $X:$ mean; SD: standard deviation; RCP: Reactive C-protein.
} 
Because metabolic diseases are associated to a set of progressive changes that occur throughout life, table 4 presented an analysis of regression related with individuals with fatty liver and to factors associated with relative risk in the development. We found that determiners had distinct relative risk. Physical inactivity can be one of the main reasons to explain the development of fatty liver.

Table 4. Odds ratio by independent determiners in adult men

\begin{tabular}{lcc}
\hline \multirow{2}{*}{ Independent variables } & \multicolumn{2}{c}{ Presence of fatty liver } \\
\cline { 2 - 3 } & Odds ratio (Cl 95\%) & Wald-p \\
\hline Physical activity (without adjust) & 1.00 & \\
Active & $10.68(7.42-15.37)$ & $0.001^{*}$ \\
Inactive & & \\
PA adjusted by age & 1.00 & $0.001^{*}$ \\
Active & $11.38(7.86-16.47)$ & \\
Inactive & & $0.001^{*}$ \\
PA adjusted by BMl & 1.00 & \\
Active & $9.84(6.69-14.47)$ & $0.001^{*}$ \\
Inactive & & 1.00 \\
PA adjusted by MS & $9.77(6.74-14.17)$ & \\
Active &
\end{tabular}

*Wald test for heterogeneity. C195\%: 95\% confidence interval; PA: physical activity; BMI: body mass index; MS: metabolic syndrome.

Low level of physical activity showed a significant impact in development of fatty liver. Inactive individuals had odds ratio 10.68 times higher to have fatty liver than active individuals. A more complex effect is observed because of age adjustment in which odds ratio was 11.00 times higher. Adjust because of BMI in inactive adults had odds ratio 9.84 times higher than active adults, adjust by the presence of metabolic syndrome was 9.77.

\section{DISCUSSION}

In Brazil, 54.5\% of adult men are overweight according to VIGITEL data, ${ }^{(15)}$ in addition the percentage of obesity is $17.5 \%$. The relationship between physical activity level and antropometrical measures of the our study showed that active men had better control of body weight, once active men BMI were closer to what is considered eutrophic $\left(1.8 \mathrm{~kg} / \mathrm{m}^{2}\right.$ low in relation with inactive men).

According to study by Carvalho et al.,(16) a higher prevalence of fatty liver diagnosis is seen among obese individuals with increased waist circumference. Waist circumference, which is measure considered as a metabolic risk factor and of cardiovascular disease development, had significant difference between physical activity levels in our study. We also observed that mean value of waist circumference of inactive adults without fatty liver is higher than active adults with fatty liver. These data suggest that physical activity seems to be a protective factor for development of fatty liver. Therefore, this information enable to affirm that, as stated by Lonardo et al., ${ }^{(17)}$ obesity, specially associated to abdominal area, promotes a response imbalance to insulin, leptin, GLP=1 and adiponectin, which can change the standard metabolic response of lipolysis favoring the fatty liver development.

Targher et al. ${ }^{(18)}$ stated that other pro-inflammatory substance is RCP and it is used as inflammatory marker related to development risk of both heart diseases and metabolic diseases. The analysis of RCP in this study, led us to conclude that inactive men with fatty liver had an increased metabolic risk and cardiovascular risk than other groups.

Glycemic behavior presented significant difference between adults with fatty liver and adults without fatty liver in both active and inactive groups, however, values considered healthy have been observed. In active individuals, a significant difference was seen in gammaglutamyl transpeptidase and alanine transaminase. Although the group with fatty liver presented higher values than those without fatty liver, they were within the normal range. Among inactive individuals, a significant difference in values of gamma-glutamyl transpeptidase, aspartate transaminase and alanine transaminase were seen. Despite this, values were within normal range.

One of hypothesis of the study suggests that physical activity serves a protective effect, especially in the use of fatty acid as substrates of energy in the metabolism. This effect occurs because there is a variety of stressful events in the liver that depend on levels of hormone circulation, liver expression of receptors of these hormones and release of growth hormone $(\mathrm{GH}),{ }^{(17)}$ once the concentration of $\mathrm{GH}$ is associated with transaminases levels and fatty liver development in men. Hence, GH must be considered significantly correlated with eating habits, regular exercise and target factors in fatty liver treatment. ${ }^{(19)}$

According to Angulo, ${ }^{(20)}$ main laboratorial changes found in individuals with fatty liver are levels of liver enzymes mainly aspartate transaminase, alanine transaminase and gamma-glutamyl transpeptidase. Targher et al. ${ }^{(18)}$ stated that high levels of liver enzymes, mainly the aspartate transaminase, indicated live inflammation and cardiovascular risk. Lee et al. ${ }^{(21)}$ affirmed that gamma-glutamyl transpeptidase performs an important function in antioxidant defense system and high levels are markers of oxidative stress and 
subclinical inflammation. Elevated transaminase levels are correlated to moderate and severe degrees of fatty liver, ${ }^{(22)}$ specially elevated rates of aspartate transaminase that give sign of progress of fatty liver in fatty liver. ${ }^{(23)}$ According to data of found in our study, men with fatty liver had statistically significant high levels of gamma-glutamyl transpeptidase, aspartate transaminase and alanine transaminase compared with those without fatty liver. Such results show that, although they were within values considered normal, individuals had large rates of hepatic enzyme, reflecting one of largest oxidative stress in comparison with healthy group. Angulo, ${ }^{(20)}$ Adams et al. ${ }^{(1)}$ and Soler et al. ${ }^{(2)}$ showed that increase of triglycerides in hepatocyte is not well explained, but provoke changes in synthesis, degradation of liver lipids, which result in increase in the resistance to insulin. ${ }^{(20)}$

The study of Couillard et al. ${ }^{(24)}$ reported that regular exercise improves HDL-c that is followed by reduce in concentration of triglycerides, which agree with data of our study, associated with abdominal obesity and insulin resistance being important factors for fatty liver treatment. Carvalho et al. ${ }^{(16)}$ reported the importance of the early diagnosis of nonalcoholic fatty liver disease development in order to enable an improvement in patients' life style especially concerning eating habits and practice of exercise. Such habits and activity combined with treatment and pharmacological control against nonalcoholic fatty liver, such as type 2 diabetes mellitus and cardiovascular diseases. Our study results showed that individuals did not reach the minimal recommendation of physical activity (150 minutes/week), had lower values of HDL-c, high triglycerides rate, obesity and high glycemic index.

Our data corroborate the findings of Adams et al. ${ }^{(1)}$ and Targher et al. ${ }^{(18)}$ affirming that main treatment for fatty liver is weight loss and control of metabolic risk factors. These factors had significant action concerning practice of exercise in these both studies.

Assessing the characteristics presented by logistic regression, the relationship of level of physical activity adjusted with metabolic syndrome and BMI showed that, even with healthy weight and without diagnosis of metabolic syndrome, the individual had higher odds ratio of developing fatty liver due to inactive. Therefore, physical activity can be considered a protective factor against the development of fatty liver and the increase of level of exercise seem to prevent fatty liver.

Although, our study is limited to determine the ideal characteristics of physical activity, i.e., intensity, type, duration and frequency - factors that can be responsible for the success of practice of exercise because of the difference of metabolic route used as energy source and energetic consumption - we believe that physical activity can be considered as preventive factor for development of fatty liver.

\section{CONCLUSION}

This study shows an association between level of physical activity and prevalence of fatty liver, i.e., individuals who exercise more had lower prevalence of fatty liver.

\section{REFERENCES}

1. Adams LA, Angulo P, Lindor KD. Nonalcoholic fatty liver disease. CMAJ 2005;172(7):899-905. Review.

2. Soler GL, Silva AW, Silva VC, Teixeira RJ. Doença Hepática Gordurosa Não Alcoólica: associação com síndrome metabólica e fatores de risco cardiovascular. Rev SOCERJ. 2008;21(2):94-100.

3. Pratt M, Sarmiento OL, Montes F, Ogilvie D, Marcus BH, Perez LG, Brownson $\mathrm{R}$, for the Lancet Physical Activity Series Working Group. The implications of megatrends in information and communication technology and transportation for changes in global physical activity. Lancet. 2012;380(9838):282-93. Review.

4. Belmonte MA, Aoki MS, Tavares FL, Seelaender MC. Rat myocellular and perimysial intramuscular triacyglycerol: a histological approach. Med Sci Sports Exerc. 2004;36(1): 60-7.

5. Lira FS. Regulação do metabolismo Hepático de Lipídios: Impacto do exercício Físico sobre a esteatose hepática não-alcoólica. Revista Mackenzie de Educação Física e Esporte. 2010;9(1):132-5

6. Rector SR, Tryfault JP, Morris RT, Laye MJ, Borengasser SJ, Booth FW, et al. Daily exercise increases hepatic fatty acid oxidation and prevents steatosis in Otsuka Long- Evans Tokushima Fatty rats. Am J Physiol Gastrointest Liver Physiol. 2008;294(3):G619-26.

7. Keating SE, Hackett DA, George J, Johnson NA. Exercise and non-alcoholic fatty liver disease: a systematic review and meta-analysis. J Hepatol. 2012; 57(1):157-66. Review.

8. Colberg SR, Sigal RJ, Fernhall B, Regensteiner JG, Blissmer BJ, Rubin RR, Chasan-Taber L, Albright AL, Braun B; American College of Sports Medicine; American Diabetes Association. Exercise and Type 2 Diabetes: the American College of Sports Medicine and the American Diabetes Association: joint position statement. Diabetes Care. 2010;33(12):e147-67.

9. Ellestad MH, Allen W, Wan MC, Kemp GL. Maximal treadmill stress testing for cardiovascular evaluation. Circulation. 1969;39(4):517-22.

10. IV Brazilian Guidelines in Arterial Hypertension Work Groups. [IV Brazilian guidelines in arterial hypertension]. Arq Bras Cardiol. 2004;82(Suppl 4):7-22. English.

11. Perloff D, Grim C, Flack J, Frohlich ED, Hill M, McDonald M, et al. Human blood pressure determination by sphygmomanometry. Circulation.1993;88(5 Pt 1): 2460-70.

12. Expert Panel on Detection, Evaluation, and Treatment of High Blood Cholesterol in Adults. Executive summary of the Third Report of the National Cholesterol Education Program (NCEP) expert panel on detection, evaluation and treatment of high blood cholesterol in adults (Adult Treatment Panel III). JAMA. 2001;285(19): 2486-97

13. Saunders JB, Aasland OG, Babor TF, de la Fuente JR, Grant M. Development of the Alcohol Use Disorders Identification Test (AUDIT): WHO Collaborative Project on Early Detection of Persons with Harmful Alcohol Consumption-II. Addiction. 1993;88 (6):791-804.

14. Matsudo S, Araújo T, Matsudo V, Andrade D, Andrade E, Oliveira LC, et al Questionário internacional de atividade física(IPAQ): estudo de validade e reprodutibilidade no Brasil. Rev Bras Ativ Fís Saúde. 2001;6(2):5-18. 
15. Brasil. Ministério da Saúde. Vigitel. Brasília, DF: Ministério da Saúde: 2014.

16. Carvalho JA, Barengo NC, Tuomilehto J, Conceição RD, Santos RD. The finnish Diabetes Risk Score (FINDRISC) as a screening tool for hepatic steatosis. Ann Med. 2011;43(6):487-94.

17. Lonardo A, Carani C, Carulli N, Loria P. Endocrine NAFLD' a hormonocentric perspective of nonalcoholic fatty liver disease pathogenesis. J Hepatol. 2006; 44(6):1196-207. Review.

18. Targher G, Day CP, Bonora E. Risk cardiovascular disease in patients with nonalcoholic fatty liver disease. N Engl J Med. 2010;363(14):1341-50. Review.

19. Leung KC, Johannsson G, Leong GM, Ho KKY. Estrogen regulation of growth hormone action. Endocr Rev. 2004;25(5):693-721. Review.

20. Angulo P. Nonalcoholic fatty liver disease. N Engl J Med. 2002;346(16):1221-31. Review.

21. Lee DS, Evans JC, Robins SJ, Wilson PW, Albano I, Fox CS, et al. Gamma glutamyl transferase and metabolic syndrome, cardiovascular disease, and mortality risk: the Framingham Heart Study. Arterioscler Thromb Vasc Biol. 2007;27(1):127-33.

22. Franzese A, Vajro P, Argenziano A, Puzziello A, lannucci MP, Saviano MC, et al. Liver involvement in obese children (ultrasonography and liver enzyme levels at diagnosis and during fallow-up in an Italian population. Dig Dis Sci. 1997;42(7):1428-32.

23. Patton HM, Sirlin C, Behling C, Middleton M, Schwimmer JB, Lavine JE. Pediatric nonalcoholic fatty liver disease: a critical appraisal of current data implications for future research. J Pediatr Gastroenterol Nutr. 2006;43(4):413-27. Review.

24. Couillard C, Després JP, Lamarche B, Bergeron J, Gagnon J, Leon AS, et al. Effects of endurance exercise training on plasma HDL cholesterol levels depend on levels of triglycerides: evidence from men of the Health, Risk Factors, Exercise Training and Genetics (HERITAGE) Family Study. Arterioscler Thromb Vasc Biol. 2001;21(7):1226-32. 